\title{
Physiological changes in obesity and patient preparation for bariatric surgery
}

\author{
Tevfik Tolga Şahin \\ Department of General Surgery, Hacettepe University Faculty of Medicine, Ankara, Turkey
}

\begin{abstract}
Morbid obesity is pandemic. Regardless of the socioeconomic status of the population, incidence of obesity is increasing worldwide. Bariatric surgery provides the only stable means of surgical cure for obesity. Number of bariatric procedures performed is increasing around the world. Morbidly obese patients are physiologically prone to complications after such major surgery. In the present review, the mechanisms of obesity and altered organ systems were discussed, and a brief summary of key points in preoperative patient evaluation was explained.
\end{abstract}

Keywords: Adiponectin; ghrelin; hormones; insulin, obesity; patient preparation; physiology.

\section{Introduction}

Obesity is a clinical condition where energy expenditure is overwhelmed by intake resulting in the accumulation of fatty tissue which leads to systemic disease and reduced life span in the individual. Obesity is a systemic disease with a complex interplay of environmental and genetic factors. ${ }^{[1]}$ It is now a major health problem of this century not only due to the fact that it threatens life of the affected individual but also due to major psychosocial implications and social discriminations towards obese individuals. ${ }^{[2]}$

Obesity rates are increasing worldwide, and there will be more than 700 million obese people by 2015 as predicted by the World Health Organization. ${ }^{[3,4]}$ According to the 2010 nutritional health assessment report of the Ministry of Health in Turkey, $61 \%$ of the male population and $50.2 \%$ of the female population are overweight or obese in Turkey. The rate of morbid obesity is $15.6 \%$ in the male and $16.6 \%$ in the female population. ${ }^{[5]}$
The etiology of obesity is multifactorial, and therefore, the exact pathophysiology of the disease is still unclear. Factors that contribute to the development of obesity are summarized in Table 2. The things that are elucidated currently are small pieces of information regarding certain aspects of the disease. Spectrum of the diseases attributable to obesity are summarized in Table 2 . The exact molecular, cellular mechanisms that play role in integration of obesity with these complex diseases are not fully understood. However, the answers seem to lie in the gut hormones.

The term metabolic syndrome is used to describe the association of truncalobesity with hypertension, hyperlipidemia, glucose intolerance, and insulin resistance that highlights the importance of excess adiposity in causing metabolic imbalance ${ }^{[6]}$ This clinical phenomenon has two main components, one of which is inflammation and the 


\section{Table 1. Etiology of obesity}

\section{Factors contributing to the development of obesity}

Social factors (such as ease of accessibility to high caloric diets)

Sedentary life (reducing energy expenditure)

Genetic and epigenetic factors

\section{Table 2. Obesity related disorders according to}

systems

\section{Obesity related disorders}

Cardiovascular system

Hypertension

Coronary artery disease

Varicose diseases of the veins

Metabolism

Type 2 diabetes mellitus

Hypercholesterolemia

Hypertriglyceridemia

Endocrine and genitourinary system

Sex hormone problems (hirsutism in women and impotence in men)

Syndrome $\mathrm{X}$

Urinary incontinence

Musculoskeletal system

Degenerative osteoarthritis

Gastrointestinal system

Gastroesophageal reflux

Hiatal hernia

Hepatosteatosis and hepatomegaly

Increased gastrointestinal cancer risk

Central nervous system

Head aches

Mechanical back pain

Respiratory system

Obstructive sleep apnea syndrome

Dyspnea

Exercise dyspnea

Hematologic system

Hypercoagulability

Thromboembolic disease

other is insulin resistance. ${ }^{[7]}$ Almost all obese individuals experience certain components of metabolic syndrome.

The aim of the present review was to discuss the possible physiologic mechanisms of obesity inguidance of the cur- rent literature. The main components of the manuscript include the mechanisms of control of feeding, the role of gut hormones in control of appetite and energy metabolism, the changes of gut absorption of carbohydrates, and mechanisms governing obesity and increased risk of systemic disease. We tried to integrate these subsections to the general picture in the obese individuals; in other words, we tried to demonstrate how these cause comorbidities in the obese individual and what the bariatric and metabolic surgeon should do in the preoperative period to evaluate these patients.

\section{Mechanisms of Appetite Control}

In a normal individual, energy intake and expenditure is balanced and the weight of the individual is in a dynamic steady state. ${ }^{[7]}$ Normally, there is a negative feedback mechanism between peripheral fatty tissue and appetite of the individual, which was first described in 1953 by Kennedy et al. ${ }^{[8]}$ The alterations in these surveillance mechanisms leading to obesity are not entirely known. In the present section, it was aimed to summarize the alterations in mechanisms of appetite control leading to obesity.

\section{The Role of Central Nervous System in Control of Appetite}

The area of the brain that plays role in the regulation of energy balance is the arcuate nucleus (AN) of the hypothalamus which has neuropeptide Y/Agouti-related protein (NPY/ARP)-expressing neurons that are suppressed by insulin, leptin, and peptide tyrosine tyorsine ( $\left.\mathrm{PYY}_{3-36}\right)$, and stimulated by gut hormones like ghrelin. ${ }^{[7,9]} \mathrm{AN}$ (NPY/ ARP neurons) is in lateral hypothalamic and perifornical area containing neuropeptide which infleuncesan increase in appetite. ${ }^{[9]}$ Another group of neurons in the AN express proopiomelanocortin and cocaine- and amphetamine related transcript (PCAT neurons) which are stimulated by leptin and inhibited by the NPY/ARP neurons. ${ }^{[10]}$ In animal models as well as human studies, leptin has caused decreased food intake and weight loss through the stimulation of the PCAT neurons. The AN of the hypothalamus and the lateral hypothalamic nuclei receive the input from the peripheral signals of appetite control (e.g. Ghrelin, leptin, insulin, adiponectin, $\mathrm{PYY}_{3-36}$, VIP etc.) and process this information and obtain feedback about the overall energy stores from the periphery and relay this information to higher centers such as the ventral tegmental area of the mesolimbic system, which is implicated in the pleasure experience of feeding. ${ }^{[-11]}$ 


\section{The Role of Peripheral Feedback Mechanisms for Appetite Control}

The so-called short-term polypeptide hormonal signals, which are called the orexigens (eg., ghrelin), stimulate hunger before a meal, and therefore, increase the food seeking behavior of the individual. Other polypeptide signals promote satiety and cause the organism to stop the feeding behavior after a meal, which generally termed the anorectic factors [eg., oxyntomodulin (OXM), peptide tyrosine tyrosine (PYY ${ }_{3-36}$ ), glucagon-like peptide-1 (GLP-1), cholecystokinin (CCK)]. ${ }^{[12,13]}$ On the other hand, long-term signals are related to total body energy stores (eg., ghrelin, insulin, leptin), and they play role in the surveillance and regulation of the efficacy of short-term signals to defend against deviations away from a weight threshold. ${ }^{[12,13]}$

\section{The Role of Gut Hormones in Control of Appetite and Energy Metabolism}

There is restriction effect in bariatric surgical procedures, and in procedures like gastric bypass, there is a malabsorbtive component. As a natural result of this, there is restriction in caloric intake of the individual, so called the "starvation" period. However, even in this negative balance state, most probably anorectic stimuli is over whelming the orexigenic stimuli because these patients do not go in to a food seeking behavior. There is one study by Marceau et al. ${ }^{[14]}$ reporting accelerated satiety after duodenal switch operation, which is actually the most malabsorbtive procedure among the others. Gut endocrine system may be the answer to this phenomenon. Therefore, gut plays a central role in feedback control of appetite and energy hemostasis. Here, we emphasized six gut-related hormones that seems to have a crucial role in appetite control.

\section{Ghrelin}

Ghrelin is a polypeptide that is synthesized and secreted from the diffuse endothelial system and the brain. It was first discovered as the endogenous ligand for the growth hormone secretagogue receptor in the hypophyseal gland. [15] Only in a later period it was discovered that ghrelin caused an increase in appetite and weight gain, and since then, it has been studied in animal models extensively. ${ }^{[16]}$ The greatest synthesis and secretion of circulating ghrelin seems to be from the ghrelin cells (P/D1 cells) located in the oxyntic glands of the fundus and body of the stomach. It shows an ultradian rhythm rising during the day and reaching a maximum level before the meals. ${ }^{[17]}$ This rhythm is achieved by the clock genes, PER1 and PER2, which are expressed by the P/D1 cells. ${ }^{[16,17]}$ The peak in ghrelin level is followed by craving for food and eating is started by the individual. After feeding, ghrelin levels start to decrease rapidly. ${ }^{[15-17]}$ Vagus nerve is one pathway that ghrelin exerts its effects, but the main mechanism of action is direct stimulation of the parts of brain that play role in the energy hemostasis of the individual. These centers are in the AN, nucleus accumbens, parabrachial nucleus, dorsomedial and lateral hypothalamic area and the subfornical part of the circum ventricular organs. In the AN, ghrelin's orexigenic effect is mediated by the stimulation of NPY/ARP neurons. ${ }^{[7]}$ It is known to increase following exercise, and therefore, it is the major factor in setting the weight threshold and also main factor in the failure of diet and exercise programs in the treatment of obesity. ${ }^{[7,17]}$

\section{Glucagon Like Peptide-1 (GLP-1)}

GLP-1, a member of the enteroglucagon family of polypeptide hormones, is derived from posttranslational processing of the preproglucagon gene product. ${ }^{[18]}$ GLP-1 is in fact a neurotransmitter in certain parts of the brain such as the paraventricular nucleus, dorsomedial hypothalamus, dorsovagal complex, thalamus, and pituitary. Its half-life is two minutes and it is eliminated by the kidneys by the enzyme dipeptidyl peptidase IV (DPP-IV). GLP-1 is secreted together with other members of the enteroglucagon family PYY ${ }_{3-36}$ and OXM by the group of endocrine cells called the L-cells in the distal small intestine. Meal is the main stimulus for the secretion of the enteroglucagons. GLP-1 and its receptor interaction exerts its effects through Gprotein as the secondary messenger and is present in multiple sites including the pancreas, stomach, and brain. ${ }^{[19]}$ Animal models have shown that both GLP-1 and $\mathrm{PYY}_{3-36}$ inhibit feeding when peripherally administered and is involved with reduction in eating behavior. GLP-1, $\mathrm{PYY}_{3-36}$, CCK and OXM are all anorectic hormones, signaling to the central nervous system that the energy intake is adequate and promote satiety. They reduce gastric emptying and acid secretion. ${ }^{[18,19]}$ Therefore, they reduce intestinal motility, provide adequate time for digestion and absorption of nutrients in the intestine. ${ }^{[20]}$

Incretin effect is the increased insulin response to enteral as opposed to parenteral glucose, and GLP-1 is one of the incretin hormones in the gut neuroendocrine system. [18-21] GLP-1 increases insulin secretion from beta cells. It in hibits glucagon secretion, and therefore, contributes 
to increased insulin sensitivity. It also promotes beta cell regeneration. ${ }^{[19,21]}$

\section{Peptide Tyrosine Tyrosine}

PYY1-36 is from the enteroglucagon family and is secreted from L-cells of the distal small bowel and colon in proportion to caloric content of a meal. It is secreted together with the active form which is the PYY ${ }_{3-36}$ and the circulating form which is PYY1-36, and transition occurs at the tissue level by DPP-IV. ${ }^{[22]}$ It responds relatively quickly to meals; levels start to rise in 15 minutes and the peak is reached within 1-2 hours. ${ }^{[23]} \mathrm{PYY}_{3-36}$ is a relatively new gut hormone first described in 2002, and similar to GLP-1 it is an anorectic factor. It reduces appetite through CNS, and furthermore, it reduces gastric emptying, pancreatic exocrine function and intestinal motility. ${ }^{[22,23]}$

A reduced $\mathrm{PYY}_{3-36}$ response to feeding has been identified in obese subjects and may represent one cause of excessive appetite. ${ }^{[2]} \mathrm{PYY}_{3-36}$ acts on the AN via Y2 receptors expressed on NPY/ARP neurons. Same receptors are expressed on solitary tract and nodose ganglion of the vagus nerve. ${ }^{[25]}$ Most probably, the anorectic effects of $\mathrm{PYY}_{3-36}$ are mediated through the vagal nerve. ${ }^{[24,25,26]}$

\section{Insulin}

Insulin is synthesized and secreted from pancreatic beta cells. Hyperglycemia following the meal is the main stimulus for insulinsecretion. ${ }^{[27]}$ Other factors that promote insulin synthesis and secretion are some amino acids such as alanine, glycine, arginine; vagal nerve (acetyl choline), incretins [GLP-1 and glucose-dependent insulinotropic polypeptide (GIP)]. ${ }^{[2]}$ It has many actions related to energy balance. Postprandial spikes of insulin result in glycogen storage in tissues such as muscle and liver and also triglycerides in the adipose tissues. ${ }^{[28]}$ When insulin action is opposed like in afasting state, it causes glucose mobilization from liver and free fatty acid mobilization from the adipose tissue. ${ }^{[28]}$ Insulin acts directly on CNS and has a negative feedback action. In animal models, when it was centrally injected, it was observed that it caused reduced appetite and weight loss. ${ }^{[27,28]}$ Insulin inhibits NPY/ARP neurons in the AN. It is a direct indicator of energy stores of the individuals. Basal insulin secretion is higher in obese individuals than in normal weight individuals. ${ }^{[27,28]}$

\section{Leptin}

Leptin is a polypeptide that is an indicator of overall body stores of the body, and its levels in the body are proportionate to the total body fat stores. It is mainly synthesized and secreted from the adipose tissue. ${ }^{[9]}$ Leptin is produced in many sites in the body and mainly in white adipose tissue, other sites are brown adipose tissue, placenta, ovaries, skeletal muscle, stomach, breast, bone marrow, pituitarygland and liver. ${ }^{[9]}$ Leptin inhibits hypothalamic NPY/ ARP neurons in the AN. On the other hand, it stimulates amelanocyte stimulating hormone exhibiting neurons. Its receptor is $\mathrm{OB}-\mathrm{Rb}$ receptor and secondary messenger is the JAK-STAT and MAPK pathway. ${ }^{[3]}$ It is counter-regulatory to ghrelin. It was successful in reducing appetite when administered in animal models; however, its role in humans are unknown because obese individuals taking leptin analogues showed minimal response which may be suggestive of a leptin resistance in obese individuals. ${ }^{\left[{ }^{[9]}\right.}$

\section{Adiponectin}

It is a high molecular weight polypeptide synthesized and secreted from the white adipose tissue. Reduced adiponectin levels are observed with the increasing body weight, body mass index (BMI) and body fat stores. ${ }^{[28]}$ Reduced fasting serum adiponectin levels were observed in obese individuals in comparison to the non-obese individuals. ${ }^{[28]}$ It may have a role in insulin resistance in T2DM. Animal models have shown increase gluconeogenesis and muscle utilization of the glucose. ${ }^{[29]}$ Human studies have revealed that high levels of adiponectin in T2DM were protective against insulin resistance. ${ }^{[29-32]}$

\section{The Metabolic Effect of These Humoral Changes}

In the surplus of caloric state and these altered metabolic mechanisms cause stimulus for new adipogenesis. However, adipogenesis is altered in obese individuals, and there is hypertrophy of the adipose tissue in the individuals. ${ }^{[33]}$ The altered neurohumoral mechanisms cause ectopic fat accumulation in the intra-abdominal, pericardial, periosteal areas, pancreatic islands and skeletal muscle, which causes a lipotoxicitydys function in the organ systems. This phenomenon is responsible for the comorbidities seen in obese individuals. ${ }^{[34,35]}$

\section{Changes in Gut Absorption of Carbohydrates}

In many studies, it has been suggested by researchers that intestinal absorption of nutrients is more rapid and efficient in obese than non-obese humans which may be the underlying mechanism to both weight gain and type 2 
diabetes. ${ }^{[36-41]}$ Animal experiments have shown that intestinal glucose absorption is dependent on the presence of luminal glucose or sweet nutrients via activation of intestinal sweet taste receptors (STRs), which are heterodimers of G-protein-coupled receptors. ${ }^{[36,37]}$ When activated, the capacity of these receptors increase the availability of intestinal sodium-dependent glucose cotransporter-1 (SGLT1) and glucose transporter-2 (GLUT2). ${ }^{[37,38]}$ These are all important transporters for glucose absorption. ${ }^{[39]}$ Activation of STRs and/or glucose transporters (GTs) has also been reported to trigger the release of incretin hormones. ${ }^{[40]} \mathrm{Ge}-$ netically modified animal models have shown that there is 7-fold higher levels of SGLT-1 protein and an increased rate of intestinal glucose absorption and visceral obesity. ${ }^{[39,40]}$ Nguyen et al. have shown that obese individuals have rapid proximal intestinal glucose absorption which is linked to increased SGLT-1 expression which results in hyperinsulinemia and hyperglycemia. ${ }^{[41]}$

\section{Mechanisms Governing Obesity and Increased Risk of Systemic Disease}

In visceral obesity, problems exist in the lipid profile of the individuals. ${ }^{[42]}$ Triglyceride (TG) and low density lipoprotein (LDL) levels are increased, and on the contrary, high density lipoprotein levels are reduced (HDL). ${ }^{[43]}$ This imbalance in lipid profile causes visceral fat accumulation and increased atherogenesis. ${ }^{[42,43]}$ Obesity mainly affects the liver, musculoskeletal, respiratory, and cardiovascular and coagulation system. If we try to summarize each system separately:

\section{Liver}

We have the reasons of metabolic changes and the development of dyslipidemia and hyperinsulinemia. As a result, over production of TAG occurs in the liverof obese individuals in the setting of energy surplus. ${ }^{[44]}$ Excessive TAG is stored as lipid droplets, which causes inflammatory reaction as a result of this non-alcoholic steatohepatitisensues. ${ }^{[44]}$ This clinical phenomenon may indeed progress to fibrosis and cirrhosis. ${ }^{[44-46]}$

\section{Musculoskeletal System}

In obese individuals changes occur in muscle structure and function. ${ }^{[47]}$ The muscle mass of obese individuals is lower than lean individuals, which is called sarcopenic body habitus. ${ }^{[47]}$ Furthermore, less functional type $2 \mathrm{~b}$ muscle fibers are dominant meaning less lipid oxidation and consumption. In the case of energy surplus, these muscle fiber types accumulate lipid droplets. ${ }^{[47]}$ In addition to all, super-obese individuals have blunted myocyte response to insulin. These factors all contribute to insulin resistance in obese individuals. Fortunately, type $2 \mathrm{~b}$ fibers increase lipid consumption as a fuel in the case of increased physical activity.

\section{Cardiovascular System}

The mechanisms of insulin resistance were explained in previous sections. Insulin resistance increases lipid synthesis in the liver and lipolysis in the adipose tissue. ${ }^{[43]} \mathrm{All}$ of these factors increase circulating free fatty acids (FFA). ${ }^{[44]}$ Myocardium starts to use FFA as the fuel, causing lipotoxicity of the muscle cells and cardiac dysfunction. ${ }^{[43,44]}$ Hyperglycemia, as a result of insulin resistance, also causes glucotoxicity in the myocardium by over producing reactive oxygen species LDL, in circulation, increases in obesity as a result of altered lipid profile, leading to atheroma formation in the coronary arteries which is an ischemic insult. ${ }^{[43,44]}$

\section{Respiratory System}

Four clinical conditions can be seen in obesity with increasing body mass index. First one is obstructive sleep apnea syndrome caused by the collapse of the upper airway and reduction in oxyhemoglobin during sleep, leading to frequent arousals from sleep period and daytime sleepiness and fatigue. Weight reduction reduces these episodes. ${ }^{[48]}$

Obstructive hypoventilation syndrome or Pickwickian syndrome is hypoventilation in awake state, and hypercapnia is usually seen in obese individuals with a BMI $\geq 30$ $\mathrm{kg} / \mathrm{m}^{2} .^{[49]}$ Overlapping syndrome is the presence of chronic obstructive pulmonary disease and obstructive sleep apnea syndrome. ${ }^{[48,49]}$

Malignant obesity hypoventilation syndrome is the obesity hypoventilation syndrome encountered together with systemic hypertension, metabolic syndrome, left ventricular hypertrophy and either pulmonary, liver or hepatic failure. This usually occurs in BMI $>40 \mathrm{~kg} / \mathrm{m}^{2}$. This patient group has high operative mortality although bariatric surgery reverses this condition. ${ }^{[48,49]}$

\section{Venous Thromboembolism in Obesity}

Obesity produces a proinflammatory and prothrombotic 
state that increases tendency towards venous thromboembolism. ${ }^{[4,50]}$ In obese individuals it has been shown that the venous return from the lower extremity is reduced. [49,50] Altered hemodynamics produces atendency towards deep vein thrombosis. ${ }^{[49,50]}$ Furthermore, elevated leptin and increased oxidative stress (endothelial cell damage) cause increased coagulation cascade activity and reduced fibrinolysis. ${ }^{[49,50]}$

\section{Obesity and Cancer}

Obesity correlates with some types of cancer such as renal cell cancer, colorecal cancer, breast cancer, prostate cancer and endometrial cancer. ${ }^{[51-53]}$ Nowadays, this is a greater concern since the onset of obesity has reduced down to childhood and the so-called exposure time has increased. Therefore, obesity related cancer incidence may increase in the future. ${ }^{[51]}$ In order to evaluate the mechanisms of oncogenesis in obesity is out of the scope of the present study; however, there are three mechanisms mainly investigated until now. ${ }^{[51]}$ First one is the low grade inflammation in obesity due to inflammatory cytokines released. Second one is the leptin peak in obesity leading to oncogenic activation. ${ }^{[52]}$ Third and the least studied mechanism is the reduction of Adiponect in which causes a loss of surveillance mechanism of proliferation and metastasis. ${ }^{[52,53]}$ Table 3 summarizes the possible mechanisms of obesity and cancer interaction.

\section{Preoperative Evaluation and Patient Preparation for Bariatric Surgery}

Under the guidance of the information given in the previous sections,we tried to summarize the basis of patient evaluation and preparationin this main subsection. We wished to mainly explain how we prepare our patients to bariatric and metabolic surgery.

\section{General Medical Evaluation}

This period involves routine evaluation of the patients for any major operation. Patient informed consent must be obtained, and during this period, patient should be informed regarding co-morbidities of obesity, surgical and anesthetic risk. A very potent education period regarding the preoperative evaluation, preparation, and most important of all, the postoperative period should be exercised. During evaluation, the following list is followed:

- Hematologic and laboratory analysis

- Chest X-ray

- Pulmonary function tests

- Electrocardiogram

- Echocardiography

- Especially in cases with multiple obesity related co-morbidities.

- Abdominal ultrasonography

- Cholelithiasis

- Hepatosteatosis

- In necessary cases abdominal computerized tomography

- Polysomnography

- Upper gastrointestinal endoscopy

- Helicobacter pylori surveillance and eradication

- Surveillance of hiatal hernia

- Surveillance of Barrett's Esophagus

- Ruling out upper gastrointestinal cancer

Routine preoperative evaluation includes complete blood count and biochemical analysis. Biochemical analysis includes liver function tests, electrolyte levels and metabolic profile. Metabolic profile of the patients should include

Table 3. Mechanisms of oncogenesis in obesity

\begin{tabular}{ll}
\multicolumn{2}{c}{ Mechanisms of Oncogenesis } \\
\hline Main pathophysiologic mechanism & End-result \\
\hline $\begin{array}{l}\text { Increased inflammatory cytokines } \\
\text { Tumor necrosis factor a (TNF-a) } \\
\text { Interleukin 6 (IL-6) } \\
\quad \text { Plasminogen activator inhibitor 1 (PAI1) }\end{array}$ & Low grade chronic inflammation \\
$\begin{array}{l}\text { Increase in leptin } \\
\text { Reduction in adiponectin }\end{array}$ & Activation of oncogenic transcription factors \\
\end{tabular}


glycosylated hemoglobin, fasting serum insulin level, Cpeptide (surrogate for intrinsic insulin secretion), thyroid function tests, and adrenal function tests. One point that is worth mentioning here is to screen the patients for vitamin $\mathrm{A}, \mathrm{C}, \mathrm{D}$ and iron since vitamin and iron deficiency is common among the surgical candidate due to extensive diet programs applied in the preoperative period. ${ }^{[54]}$ In either case, these vitamins, iron, magnesium and trace elements should be evaluated and replaced in case of any deficiencies. ${ }^{[54]}$ Preoperative deep venous thrombosis should be evaluated with Doppler ultrasonography and D-dimer measurement in patients who have physical examination findings suggestive of deep vein thrombosis (Varicose veins, positive Homans sign).

\section{Psychosocial and Behavioral Evaluation}

Psychiatric disorders such as depression, anxiety, and personality disorders affect the success of bariatric surgery. ${ }^{[55]}$ Therefore, preoperative evaluation of the patient should be thorough and include full psychiatric screening, personality analysis and surveillance for substance abuse, and furthermore, patient education is mandatory for postoperative period. ${ }^{[5,57]}$ Any maladaptive eating patterns should be treated and counselled for the success of bariatric surgery.

\section{Conclusion}

Morbidly obese patients are among high-risk patient group with an internal milieu which harbors dangers and pitfalls for a major surgery like bariatric surgery. Therefore, a thorough multidisciplinary approach for evaluating patient risks is imperative.

\section{References}

1. Lyznicki JM, Young DC, Riggs JA, Davis RM; Council on Scientific Affairs, American Medical Association. Obesity: assessment and management in primary care. Am Fam Physician 2001;63:2185-96.

2. Aronne LJ. Classification of obesity and assessment of obesity-related health risks. Obes Res 2002;10 Suppl 2:105S-115S.

3. Finelli C, Padula MC, Martelli G, Tarantino G. Could the improvement of obesity-related co-morbidities depend on modified gut hormones secretion? World J Gastroenterol 2014;20:16649-64.

4. Flegal KM, Carroll MD, Kit BK, Ogden CL. Prevalence of obesity and trends in the distribution of body mass index among US adults, 1999-2010. JAMA 2012;307:491-7.

5. Ministry of Helath of Turkish Republic Jutrional Helath Report
2010. Available at: http://www.sb.gov.tr/TR/belge/1-32407/ turkiye-beslenme-ve-saglik-arastirmasi-2010-yayinlandi. html. Accessed May 25, 2017.

6. Poole R, Byrne CD. The metabolic syndrome and type 2 diabetes. Minerva Endocrinol 2005;30:139-59.

7. Harvey EJ, Arroyo K, Korner J, Inabnet WB. Hormone changes affecting energy homeostasis after metabolic surgery. Mt Sinai J Med 2010;77:446-65.

8. Kennedy GC. The role of depot fat in the hypothalamic control of food intake in the rat. Proc R Soc Lond B Biol Sci 1953;140:578-96.

9. Cowley MA, Smart JL, Rubinstein M, Cerdán MG, Diano S, Horvath TL, et al. Leptin activates anorexigenic POMC neurons through a neural network in the arcuate nucleus. Nature 2001;411:480-4.

10. Nakazato M, Murakami N, Date $Y$, Kojima M, Matsuo H, Kangawa $K$, et al. A role for ghrelin in the central regulation of feeding. Nature 2001;409:194-8.

11. Badman MK, Flier JS. The gut and energy balance: visceral allies in the obesity wars. Science 2005;307:1909-14.

12. Flier JS. Obesity wars: molecular progress confronts an expanding epidemic. Cell 2004;116:337-50.

13. Könner AC, Klöckener T, Brüning JC. Control of energy homeostasis by insulin and leptin: targeting the arcuate nucleus and beyond. Physiol Behav 2009;97:632-8.

14. Marceau P, Cabanac M, Frankham PC, Hould FS, Lebel S, Marceau S, et al. Accelerated satiation after duodenal switch. Surg Obes Relat Dis 2005;1:408-12.

15. Cummings DE, Purnell JQ, Frayo RS, Schmidova K, Wisse $B E$, Weigle DS. A preprandial rise in plasma ghrelin levels suggests a role in meal initiation in humans. Diabetes 2001;50:1714-9.

16. Cummings DE, Weigle DS, Frayo RS, Breen PA, Ma MK, Dellinger EP, et al. Plasma ghrelin levels after diet-induced weight loss or gastric bypass surgery. N Engl J Med 2002;346:1623-30.

17. LeSauter J, Hoque N, Weintraub M, Pfaff DW, Silver R. Stomach ghrelin-secreting cells as food-entrainable circadian clocks. Proc Natl Acad Sci USA 2009;106:13582-7.

18. Neary NM, Small CJ, Druce MR, Park AJ, Ellis SM, Semjonous NM, et al. Peptide YY3-36 and glucagon-like peptide-17-36 inhibit food intake additively. Endocrinology 2005;146:51207.

19. Young AA, Gedulin BR, Rink TJ. Dose-responses for the slowing of gastric emptying in a rodent model by glucagon-like peptide (7-36) NH2, amylin, cholecystokinin, and other possible regulators of nutrient uptake. Metabolism 1996;45:1-3.

20. Soltani N, Kumar M, Glinka Y, Prud'homme GJ, Wang Q. In vivo expression of GLP-1/lgG-Fc fusion protein enhances beta-cell mass and protects against streptozotocin-induced diabetes. Gene Ther 2007;14:981-8.

21. le Roux CW, Welbourn R, Werling M, Osborne A, Kokkinos A, Laurenius $A$, et al. Gut hormones as mediators of appetite and weight loss after Roux-en-Y gastric bypass. Ann Surg 2007;246:780-5. 
22. Korner J, Inabnet W, Conwell IM, Taveras C, Daud A, Olivero-Rivera $L$, et al. Differential effects of gastric bypass and banding on circulating gut hormone and leptin levels. Obesity 2006;14:1553-61.

23. Batterham RL, Cowley MA, Small CJ, Herzog H, Cohen MA, Dakin $\mathrm{CL}$, et al. Gut hormone PYY(3-36) physiologically inhibits food intake. Nature 2002;418:650-4.

24. Batterham RL, Cohen MA, Ellis SM, Le Roux CW, Withers DJ, Frost GS, et al. Inhibition of food intake in obese subjects by peptide YY3-36. N Engl J Med 2003;349:941-8.

25. Koda S, Date $Y$, Murakami N, Shimbara T, Hanada T, Toshinai $K$, et al. The role of the vagal nerve in peripheral PYY336 -induced feeding reduction in rats. Endocrinology 2005;146:2369-75.

26. Polonsky KS, Given BD, Hirsch L, Shapiro ET, Tillil H, Beebe C, et al. Quantitative study of insulin secretion and clearance in normal and obese subjects. J Clin Invest. 1988;81:435-41.

27. Lee WJ, Ser KH, Chong K, Lee YC, Chen SC, Tsou JJ, et al. Laparoscopic sleeve gastrectomy for diabetes treatment in nonmorbidly obese patients: efficacy and change of insulin secretion. Surgery 2010;147:664-9.

28. English PJ, Coughlin SR, Hayden K, Malik IA, Wilding JP. Plasma adiponectin increases postprandially in obese, but not in lean, subjects. Obes Res 2003;11:839-44.

29. Kubota N, Terauchi Y, Yamauchi T, Kubota T, Moroi M, Matsui $J$, et al. Disruption of adiponectin causes insulin resistance and neointimal formation. J Biol Chem 2002;277:25863-6.

30. Weyer C, Funahashi T, Tanaka S, Hotta K, Matsuzawa Y, Pratley RE, et al. Hypoadiponectinemia in obesity and type 2 diabetes: close association with insulin resistance and hyperinsulinemia. J Clin Endocrinol Metab 2001;86:1930-5.

31. Spranger J, Kroke A, Möhlig M, Bergmann MM, Ristow M, Boeing $\mathrm{H}$, et al. Adiponectin and protection against type 2 diabetes mellitus. Lancet 2003;361:226-8.

32. Kotidis EV, Koliakos G, Papavramidis TS, Papavramidis ST. The effect of biliopancreatic diversion with pylorus-preserving sleeve gastrectomy and duodenal switch on fasting serum ghrelin, leptin and adiponectin levels: is there a hormonal contribution to the weight-reducing effect of this procedure? Obes Surg 2006;16:554-9.

33. Capurso C, Capurso A. From excess adiposity to insulin resistance: the role of free fatty acids. Vascul Pharmacol 2012;57:91-7.

34. Pasarica M, Xie H, Hymel D, Bray G, Greenway F, Ravussin E, et al. Lower total adipocyte number but no evidence for small adipocyte depletion in patients with type 2 diabetes. Diabetes Care 2009;32:900-2.

35. Gray SL, Vidal-Puig AJ. Adipose tissue expandability in the maintenance of metabolic homeostasis. Nutr Rev 2007;65:S7-12.

36. Fujioka S, Matsuzawa Y, Tokunaga K, Tarui S. Contribution of intra-abdominal fat accumulation to the impairment of glucose and lipid metabolism in human obesity. Metabolism 1987;36:54-9.

37. Osswald C, Baumgarten K, Stümpel F, Gorboulev V, Akim- janova $\mathrm{M}$, Knobeloch $\mathrm{KP}$, et al. Mice without the regulator gene Rsc1A1 exhibit increased Na+-D-glucose cotransport in small intestine and develop obesity. Mol Cell Biol 2005;25:78-87.

38. Ait-Omar A, Monteiro-Sepulveda M, Poitou C, Le Gall M, Cotillard A, Gilet J, et al. GLUT2 accumulation in enterocyte apical and intracellular membranes: a study in morbidly obese human subjects and ob/ob and high fat-fed mice. Diabetes 2011;60:2598-607.

39. Wu T, Zhao BR, Bound MJ, Checklin HL, Bellon M, Little TJ, et al. Effects of different sweet preloads on incretin hormone secretion, gastric emptying, and postprandial glycemia in healthy humans. Am J Clin Nutr 2012;95:78-83.

40. Steinert RE, Gerspach AC, Gutmann H, Asarian L, Drewe J, Beglinger $C$. The functional involvement of gut-expressed sweet taste receptors in glucose-stimulated secretion of glucagon-like peptide-1 (GLP-1) and peptide YY (PYY). Clin Nutr 2011;30:524-32.

41. Nguyen NQ, Debreceni TL, Bambrick JE, Chia B, Wishart J, Deane AM, et al. Accelerated intestinal glucose absorption in morbidly obese humans: relationship to glucose transporters, incretin hormones, and glycemia. J Clin Endocrinol Metab 2015;100:968-76.

42. Lamarche B, Uffelman KD, Carpentier A, Cohn JS, Steiner G, Barrett $\mathrm{PH}$, et al. Triglyceride enrichment of HDL enhances in vivo metabolic clearance of HDL apo A-I in healthy men. $J$ Clin Invest 1999;103:1191-9.

43. Taskinen MR. Diabetic dyslipidaemia: from basic research to clinical practice. Diabetologia 2003;46:733-49.

44. Vergès $B$. Abnormal hepatic apolipoprotein $B$ metabolism in type 2 diabetes. Atherosclerosis 2010;211:353-60.

45. Donnelly KL, Smith Cl, Schwarzenberg SJ, Jessurun J, Boldt MD, Parks EJ. Sources of fatty acids stored in liver and secreted via lipoproteins in patients with nonalcoholic fatty liver disease. J Clin Invest 2005;115:1343-51.

46. Brunt EM, Janney CG, Di Bisceglie AM, Neuschwander-Tetri BA, Bacon BR. Nonalcoholic steatohepatitis: a proposal for grading and staging the histological lesions. Am J Gastroenterol 1999;94:2467-74.

47. Hulver MW, Berggren JR, Cortright RN, Dudek RW, Thompson $\mathrm{RP}$, Pories WJ, et al. Skeletal muscle lipid metabolism with obesity. Am J Physiol Endocrinol Metab 2003;284:E741-7.

48. Schwartz AR, Patil SP, Laffan AM, Polotsky V, Schneider $H$, Smith PL. Obesity and obstructive sleep apnea: pathogenic mechanisms and therapeutic approaches. Proc Am Thorac Soc 2008;5:185-92.

49. Ageno W, Becattini C, Brighton T, Selby R, Kamphuisen PW. Cardiovascular risk factors and venous thromboembolism: a meta-analysis. Circulation 2008;117:93-102.

50. Darvall KA, Sam RC, Silverman SH, Bradbury AW, Adam DJ. Obesity and thrombosis. Eur J Vasc Endovasc Surg 2007;33:223-33.

51. Renehan AG, Tyson M, Egger M, Heller RF, Zwahlen M. Bodymass index and incidence of cancer: a systematic review and meta-analysis of prospective observational studies. Lancet 
2008;371:569-78.

52. Jeffreys M, Smith GD, Martin RM, Frankel S, Gunnell D. Childhood body mass index and later cancer risk: a 50-year follow-up of the Boyd Orr study. Int J Cancer 2004;112:348-51.

53. Davoodi SH, Malek-Shahabi T, Malekshahi-Moghadam A, Shahbazi R, Esmaeili S. Obesity as an important risk factor for certain types of cancer. Iran J Cancer Prev 2013;6:18694.

54. Buchwald H, Ikramuddin S, Dorman RB, Schone JL, Dixon JB. Management of the metabolic/bariatric surgery patient. Am
J Med 2011;124:1099-105.

55. Kinzl JF, Schrattenecker M, Traweger C, Mattesich M, Fiala M, Biebl W. Psychosocial predictors of weight loss after bariatric surgery. Obes Surg 2006;16:1609-14.

56. Apovian CM, Cummings S, Anderson W, Borud L, Boyer K, Day $\mathrm{K}$, et al. Best practice updates for multidisciplinary care in weight loss surgery. Obesity 2009;17:871-9.

57. Tariq N, Chand B. Presurgical evaluation and postoperative care for the bariatric patient. Gastrointest Endosc Clin N Am 2011;21:229-40. 